\title{
A singularidade na multiplicidade: crianças e tecnologias móveis na escola no contexto da cultura digital ${ }^{1}$
}

Lyana Thédiga de Miranda²

Monica Fantin ${ }^{3}$

Resumo:

O texto discute a relação entre crianças e tecnologias móveis na escola com objetivo de analisar as múltiplas linguagens e multissensorialidades envolvidas no processo de ensino-aprendizagem na perspectiva da mídia-educação. No contexto de uma investigação sobre o Projeto Um Computador por Aluno (ProUCA) em uma escola pública, desenvolveu-se uma pesquisa com crianças, de cunho qualitativo com abordagem metodológica participativa e nuances etnográficas. Tendo como pressuposto os contextos de interação entre educação, comunicação e tecnologias móveis, o artigo discute o modelo um-a-um em diálogo com a noção de ecossistema comunicativo e reflete sobre as possibilidades de uso e apropriação da tecnologia a partir de uma experiência didática desenvolvida com crianças na escola. Por fim, destaca-se a necessidade de pensar as mediações educativas contemporâneas na perspectiva das multiliteracies e de novas metodologias de ensino-aprendizagem.

Palavras-chave: crianças e multissensorialidades; tecnologias digitais móveis; Multiliteracies na escola

\footnotetext{
1 Este artigo é uma adaptação do texto Crianças e tecnologias móveis na escola: interação e mediação, apresentado no GP Comunicação e Educação, no XIII Encontro dos Grupos de Pesquisas em Comunicação, do XXXVI Congresso Brasileiro de Ciências da Comunicação, INTERCOM, 2013.

2 Jornalista, publicitária, mestre e doutoranda em Educação no Programa de Pós-graduação em Educação - linha Educação e Comunicação (ECO), PPGE/UFSC. Email: lyanathediga@gmail.com

3 Professora Associada do Centro de Ciências da Educação e do Programa de Pós-graduação em Educação - linha Educação e Comunicação (ECO), PPGE/UFSC. Líder do Grupo de Pesquisa Núcleo Infância, Comunicação, Cultura e Arte (NICA/UFSC/CNPq). Email: mfantin@terra. com.br
} 


\section{The singularity in multiplicity: children and mobile technology at school in the digital culture context}

La singularidad en la multiplicidad: los niños y las tecnologías móviles en la escuela en el contexto de la cultura digital

\section{Abstract}

The paper discusses the relationship among children and mobile technology at school with the goal to analise the multiple languages and multi-sensoriality into learning-teaching processes in the perspective on media education. In the context of researching "One Laptop Per Child", Project in public schools, qualitative investigation was developed children and through participatory ethnographical methodology. With the assumption of interaction among education, comunication and mobile technologies, this article discusses the one-to-one model, the framework about comunicative ecosystem and the uses of technology as a result of didactic experience developed with children at school. Finaly, it emphasizes the contemporary educative mediation in the multiliteracy perspectives and new methodologies to teaching and learning.

Key-words: children and multi-sensorialities; mobile digital technologies; multiliteracies at school

\section{Resumen}

En este trabajo se analiza la relación entre los niños y las tecnologías móviles en la escuela con intención de examinar las múltiples linguages y multi-sensorialidades involucrados en el proceso de enseñanza-aprendizaje desde la perspectiva de la educación en los medios. En el contexto de una investigación sobre el "Proyecto Una computadora por alumno", ProUCA, en las escuelas públicas fue desarrollada una investigación con los niños con un enfoque cualitativo y metodología participativa con matices etnográficas. Entendiéndose los contextos de interacción entre la educación, la comunicación y las tecnologías móviles, el artículo aborda el diálogo del modelo uno-a-uno con la noción de ecosistema comunicativo y reflexiona sobre las posibilidades de uso y apropiación de la tecnología en una experiencia de aprendizaje desarrollada con los niños en la escuela. Por último, se enfatiza la necesidad de pensar la mediación educativa contemporánea desde la perspectiva de las multiliteracias y de nuevas metodologías de enseñanza y aprendizaje.

Palabras clave: niños y multi-sensorialidades; tecnologías digitales móviles; Multiliteracias en la escuela 


\section{Educação, comunicação e tecnologias digitais móveis na escola: contextos em interação}

Muitas são as possibilidades de refletir sobre a relação entre educação e comunicação na escola ou fora dela. Parte da complexidade que envolve esse entorno pode ser discutida a partir do conceito de ecossistema comunicativo proposto por Martín-Barbero:

Na relação entre Educação e Comunicação, a última quase sempre é reduzida a sua dimensão puramente instrumental. É deixado de fora o que é justamente estratégico pensar: que é a inserção da educação nos complexos processos de comunicação da sociedade atual, ou falando de outro modo, pensar no ecossistema comunicativo que constitui o entorno educacional difuso e descentrado em que estamos imersos. (2004, p. 339-40)

A provocação do autor localiza uma concepção de comunicação que se caracteriza não só pela descentralização do polo emissor e receptor de uma mensagem mas, sobretudo, pela não-linearidade que configura o contexto. Nesse panorama, a ideia de que a mensagem é emitida por uma fonte de informação e recebida por um destinatário torna-se uma simplificação de um fenômeno múltiplo, no qual o processo comunicacional não é mais visto como uma simples "transmissão de dados" - linear, telegráfica e unidirecional - que desconsidera o processo de significação que ocorre no contato com o outro. Desse modo, é importante pensar o ecossistema comunicativo como uma "orquestração"1 que inclui a todos: alunos, professores, artefatos, escola, sociedade, cultura.

Essa união de diversas partes diferentes, mas que se relacionam entre si, pode ser entendida na perspectiva de uma Ecologia da Mente, como proposta por Gregory Bateson $(1977,1986)$. Pensar sob esse ponto de vista significa considerar uma organização interdisciplinar "no sentido de descobrir pautas comuns em muitas disciplinas" (BATESON,1993, p. 19), um arrolamento que congrega linguagens, aprendizagens, evolução biológica e a vida em si (WINKIN, 1981). A metáfora ecológica e sistêmica da mente e da Comunicação nos permite contemplar um liame entre esta e a Educação para além da mera instrumentalização. Com esse interesse, Bateson traçou os caminhos que o levaram a pensar no conglomerado de ideias - advindas das interações e das relações humanas (sujeito-sujeito, sujeito-natureza, natureza-sujeito) -, como um todo que, em primeira instância, busca a (re) união entre corpo e mente.

O propósito de entender como a mente "se liga" em processos interacionais (BATESON, 1986) nos leva a uma aproximação com o que James Paul Gee chama de Mente Social (1992), entendida como uma construção que engloba instâncias sociais e culturais eminentemente integradas ao mundo. De forma breve, são duas as maneiras que, para ele, caracterizam a mente como social: uma por ser um potente reconhecedor de padrões - característica própria de sua natureza - e outra por nos ligar ao conhecimento dos outros, distribuídos por meio de símbolos, ferramentas, objetos e tecnologias. Em ambas, o que está em jogo é a incidência do contexto na construção dos significados, o que Gee aponta como "world-building situated meanings" (GEE, 2000, p. 202), que extrai padrões e conhecimentos da experiência e que é a base das "classroom learning communities" (ibid, p. 196), comunidades de aprendizagem de sala de aula. Tal conceito também pode ser entendido a partir da ideia de aprendizagem socialmente situada, e das "comunidades de aprendizagem" proposta por Bruner (2001).

Esse movimento que abarca o confronto e a busca de padrões significativos de interação em determinado contexto envolve novas formas de pensar sobre o mundo e consequentemente, agir sobre ele. A essas "novas" formas de pensar e agir sobre o mundo, Lankshear e Knobel (2011, p.43) denominam "mentalidades", que se distinguem pela forma de interpretar o mundo contemporâneo. Em uma delas, a concepção do mundo é a mesma que no período "moderno-industrial" (p. 47) e mantém as mesmas características econômicas, sociais, culturais e políticas - só que mais "tecnologizada" -, uma mentalidade mecânica, linear. Noutra, a diferença está na percepção das possibilidades para novas práticas 
sociais, impulsionadoras de novas aprendizagens (new literacies), em grande parte decorrentes das tecnologias digitais móveis (p. 64).

Para os autores, tais mentalidades divergem em pontos denominados como "ontologias opostas" (ibid, p. 51). Se em uma há uma atenção na inteligência individual, na outra o foco será na inteligência coletiva; se por um lado os espaços são definidos e entendidos como lugar para finalidades rígidas e definidas, por outro, os espaços são fluidos, locais de movimento; ou ainda, se em uma concepção a tecnologia aparece como um acessório, ferramenta que "sofistica" modos de fazer historicamente instituídos, na outra as tecnologias aparecem como possibilidades para novas e diferentes interações. Ao apresentar as duas mentalidades, os autores sinalizam o surgimento de um novo ethos comunicativo, mais participativo, colaborativo e distribuído e, com ele, novas possibilidades de ver, estar e aprender com o outro, o que se aproxima do que entendemos como uma perspectiva ecológica e sistêmica da mídia-educação.

Em tal entendimento, a Comunicação se caracteriza como uma forma de agir que é contígua, tal como postulou Freire (2011), para quem não há comunicação se não houver reciprocidade, e nem compreensão sem diálogo. Desse modo, no ecossistema comunicativo e na ecologia da mente não há como pensar a educação e/ou a comunicação senão como um dos elementos em ativa interação proporcionando a troca e a influência mútua. Essa inseparabilidade entre Educação e Comunicação é redimensionada por Freire: "educação é comunicação, é diálogo, na medida em que não é transferência de saber, mas um encontro de sujeitos interlocutores que buscam a significação dos significados" (2011, p. 35).

Desta forma, ao ponderarmos um enfoque ecológico e sistêmico da comunicação orientado "a um entendimento das práticas comunicativas não apenas na sua vertente informativa e transmissiva, mas igualmente na sua vertente relacional, dialógica e vinculadora" (PINTO, 2005, p. 263) não pode ser pensado, senão, em conjunto com uma ação educativa. Perspectiva esta cara à Mídia-educação.
Na conformação dessa "nova ontologia", ou de um novo ethos comunicativo, a Mídia-educação surge como uma possibilidade de ação-reflexão e intervenção sobre a relação entre mídias, tecnologias e culturas na intersecção ou no entrelaçamento entre a educação e a comunicação (RIVOLTELLA, 2012a). Tal relação proporciona ao fazer educativo a (re)união dos sentidos e das dinâmicas culturais cada vez mais permeadas pela presença das tecnologias digitais móveis, o que requer mediações das relações entre sujeitos, culturas e tecnologias (FANTIN, 2006) que possam tonalizar, ao mesmo tempo em que retocam, as interações, as sensibilidades, e as aprendizagens contemporâneas.

Neste paradigma ecológico e sistêmico, a proposta que se pauta na Mídia-educação considera o fazer educativo como uma possibilidade, ou palco, para outras múltiplas interações, no qual o "objetivo do trabalho educativo na escola não é apenas o uso das tecnologias em laboratórios multimídia, e sim que a criança atue nesse e noutros espaços estabelecendo interações e construindo relações e significações" (FANTIN, 2006, p. 2)

Considerar o fazer escolar como parte da cultura que se constrói num ambiente permeado por diversas tecnologias e suas mediações implica a necessidade de tomar os sujeitos em interações com os artefatos nesse espaço sob a ótica ecológica e sistêmica. Nessa perspectiva - uma visão integrada que considera a criança e sua corporeidade, na qual saber fazer é tão importante quanto saber perguntar - o fazer escolar pode "articular as propostas educativas com as exigências do ambiente comunicativo a partir de cada inovação tecnológica, integrando-as umas nas outras." (FANTIN, 2006, p. 105).

E foi com esse pressuposto ecológico e sistêmico da mídia-educação que buscamos entender a relações das crianças com as tecnologias móveis no contexto de uma pesquisa sobre o ProUCA.

\section{O ProUCA em questão}

A implantação do Projeto Um Computador por Aluno, ProUCA, foi uma das bandeiras de políticas públicas go- 
vernamentais para inserção de laptops nas escolas brasileiras nos últimos anos. Iniciado com um projeto pré-piloto entre 2007 e 2009 em cinco municípios brasileiros, o piloto foi desenvolvido entre 2010 e 2012, por meio da Lei $n^{\circ} 12.249^{2}$. O projeto envolveu a distribuição de cerca de 150.000 laptops a 320 escolas públicas brasileiras em todos estados do país, atingindo cerca de 113.385 alunos e 7.025 professores (Brasil, 2010). Com suas raízes no programa One Laptop Per Child (OLPC), criado por Nicholas Negroponte, co-fundador do Media Lab do Instituto de Tecnologia de Massachusetts (MIT), o ProUCA seguiu as linhas gerais de tal discurso: a fabricação e distribuição das tecnologias digitais móveis (laptops e mais recentemente os tablets ${ }^{3}$ ) produzidas especificamente para o uso educacional com custo reduzido de forma a facilitar o acesso de alunos de baixa renda das escolas públicas. O objetivo anunciado no site do programa era estimular a cadeia produtiva e melhorar o ensino na perspectiva da inclusão digital.

No entanto, o entendimento de inclusão digital como "acesso à máquina" pode ser problematizado quando se considera o sentido de inclusão digital, social e cultural como mediação e qualidade de acesso, como é proposto por Warschauer (2006), Fantin e Girardello (2009), Bonilla e Pretto (2011). Afinal, numa perspectiva ecológica e sistêmica da mídia-educação, não é suficiente ter o acesso à tecnologia em si, pois sabemos que há um entorno ambiental que assegura ou não mediações em relação à qualidade do que se faz com o artefato diante das condições de infra-estrutura, acesso e manutenção na escola e as possibilidades de uso fora dela.

Para "melhorar a qualidade dos processos de ensino-aprendizagem nas escolas públicas brasileiras, por meio da universalização do uso de Tecnologias da Informação e da Comunicação (TIC) no sistema público de ensino" (BRASIL, 2010) é necessário, então, problematizar a contradição entre o acesso à rede e a oferta de máquinas aquém das possibilidades almejadas de uso (baixo armazenamento de memória e bateria, problemas com a ergonomia das máquinas, com teclados e telas pequenas). Assim como é fundamental discutir a ausência de infra-estrutura das escolas (poucos pontos de rede wi- reless, escassez de tomadas para a recarga das baterias e dificuldades para a manutenção dos equipamentos e outros) que dificulta ou impossibilita a operacionalização do programa e do próprio modelo 1:1 (QUARTIERO, BONILLA, FANTIN, 2012).

Importante lembrar que na abordagem construcionista que fundamenta o modelo 1:1, Papert (2008, p.137) argumenta que, no processo de aprendizagem, a mente do sujeito necessita construir objetos e dispositivos para gerar ideias, e o laptop seria este dispositivo de aprendizagem que o autor nomeia de "artefatos cognitivos". A ideia de "aprender a aprender" entendida no pressuposto do autor, considera o conhecimento como resultado de uma construção ativa do sujeito com o artefato, ou seja, os alunos aprenderiam por exploração, de forma "autônoma" e por meio da experimentação direta e "sem intervenções" nesse contato da criança com o "mundo".

Em tal quadro, seria interessante perguntar quais seriam as condições necessárias para que alunos atuem de forma "autônoma e colaborativa", como pondera o documento oficial (BRASIL, 2010) do ProUCA? Será que apenas o acesso a tais ferramentas e aos conteúdos nelas publicadas qualifica os procedimentos de ensino-aprendizagem? Sabemos que o contexto contemporâneo se caracteriza como um circuito difuso e descentrado, no qual não só a escola, mas também as políticas educacionais referentes à inserção de tecnologias digitais móveis no espaço escolar estão colocadas.

Desse modo, observar e investigar a relação entre crianças, mídia e suas tecnologias é condição para uma mediação significativa feita pelo professor de modo a entender tal interação como uma experiência cultural e parte importante de uma engrenagem que impulsiona as transformações da atualidade (Martín-Barbero, 2000). Com isso, a inclusão das tecnologias no cotidiano escolar precisa ir além da mera funcionalidade e do caráter instrumental para ser entendida na perspectiva mais ampla da relação criança-tecnologia, e do próprio modelo 1:1. A esse respeito, o modelo 1:1 proposto pelo programa também pode ser discutido quando sua ênfase reside no artefato e não nas interações que com ele se estabele- 
ce. Tanto do ponto de vista da aprendizagem como da possibilidade de uso pela família e pela comunidade, a ideia de inovação amparada na mobilidade precisa ser discutida em uma perspectiva mais ampla. Ou seja, no modelo 1:1 a ênfase situa-se na relação com a tecnologia e não em relação aos outros aspectos do ecossistema comunicativo ou da perspectiva ecológica e sistêmica mencionada anteriormente. Severin e Capota (2011) criticam certos aspectos políticos e pedagógicos desse modelo 1:1 e sugerem outro enfoque, menos centrado na tecnologia e mais voltado à aprendizagem.

Os autores preferem definir o conceito 1:1 não em relação à proporção um artefato digital por criança, mas na relação de cada criança com sua aprendizagem, em que os artefatos sejam considerados apenas um entre tantos outros fatores presentes nessa relação. Esse novo modelo 1:1

se refiere a la relación entre cada estudiante y su
aprendizaje, la cual se establece generalmente
en la escuela, pero también en y durante muchos
otros espacios y momentos, permitiendo que
podamos reconceptualizar la educación como
un proceso que se desarrolla de manera ubicua y
permanente (SEVERIN; CAPOTA, 2011, p.37)

E é com esse entendimento ecológico e sistêmico que propomos repensar a relação 1:1 como um arrolamento entre aluno e dispositivo, nesse caso o laptop, para reuni-los em torno de uma relação holística pautada no aluno, nas aprendizagens, nas interações, no ambiente e nas mediações. Tal visão ultrapassa a concepção de que a tecnologia em si é suficiente, pois o dispositivo é "mais um", e não "o" artefato no contexto de um ambiente educativo.

Com esse entendimento, é possível perceber as novas possibilidades de espaços de conexão, organização e formas de ver e significar o mundo em um processo ecológico e sistêmico de mútua afetação (BATESON, 1977, 1986) mediada pela tecnologia digital móvel. Espaços que, segundo Kerckhove, se configuram como terreno fértil para "uma nova forma de cognição intermediária, uma ponte de interação continuada, um corpus callosum entre o mundo exterior e os nossos eus interiores" (2009, p. 38).
Assim, para se pensar em outras formas de cognição é preciso questionar não apenas os processos e possibilidades técnicas, mas os processos cognitivos e culturais envolvidos nas aprendizagens. E nessa relação, a própria noção de comunicação deve ser aprendida como algo que não é inerente à relação com os artefatos tecnológicos móveis, como muitas vezes tem sido entendida nos discursos e nos programas de inserção de tecnologias nas escolas.

Nesse contexto, a metodologia da pesquisa que origina as reflexões deste artigo situa-se na articulação entre uma pesquisa macro, Gestão e práticas pedagógicas no âmbito do Programa UCA: desafios e estratégias à consolidação de uma política pública para a educação básica - UCABASC (QUARTIERO, BONILLA, FANTIN, 2012), e a especificidade do olhar micro, na pesquisa Multissensorialidades e aprendizagens das crianças com as tecnologias móveis na escola (Miranda, 2013), de onde recortamos alguns aspectos para discutir. Alguns desdobramentos investigativos de tal análise relacionam-se a outras metodologias de pesquisas (FANTIN, 2014).

Com um interesse mais específico, a pesquisa de mestrado se inseriu no eixo das Práticas Pedagógicas, objetivando compreender o papel da multissensorialidade, mediada pelo uso das tecnologias digitais móveis na construção de novas aprendizagens pelas crianças em uma escola participante do ProUCA. Para tanto, optamos por um desenho metodológico mídia-educativo (RIVOLTELLA, 2009), participativo - que se aproxima da Pesquisa-ação (THIOLLENT, 2000; TRIPP, 2012) - e com um "perfume" etnográfico (BATESON, 1986). Desse modo, acompanhamos os trabalhos desenvolvidos em turma do $3^{\circ}$ ano, com crianças entre 8 e 9 anos, durante o ano letivo de 2012, por meio de observação participante, intervenção didática, entrevistas e grupos focais com os estudantes, registrando tais atividades em um diário de campo. A pesquisa empírica extrapolou o espaço escolar ao situar a aprendizagem no diálogo com outros contextos culturais dos alunos (New London Group, 1996).

Pautando-nos em uma construção coletiva das atividades desenvolvidas na intervenção didática, buscamos 
abarcar não só a forma como alunos, professores e pesquisadores interagem e participam na escola, mas, sobretudo, como constroem suas práticas culturais nos diferentes ambientes e processos de ensino-aprendizagem.

\section{A adoção de um paradigma ecológico e sistêmico da mídia-educação na escola}

Pensar um paradigma que abarque a educação e a comunicação em seu sentido interacional, ecológico e sistêmico, sobretudo no uso das tecnologias, implica ultrapassar a simples adoção de uma perspectiva individual, linear e pautada em uma visão industrial, como diz Lankshear e Knobel (2011). Implica também pensar em um trabalho com as tecnologias móveis na perspectiva das múltiplas linguagens e multissensorialidades no contexto da inclusão digital, social e cultural em diálogo com o cotidiano escolar.

Ao problematizar em que medida os laptops propiciam mudanças no dia-a-dia da escola e nos processos de ensino-aprendizagem, no âmbito das pesquisas sobre o ProUCA, Fantin (2012) destaca a dimensão da aprendizagem multimídia enfatizando o sentido das multiliteracies. Para ela, é necessário ampliar a noção de "estar alfabetizado", que a seu ver envolve os novos letramentos e o conceito de multiliteracies articulado aos conceitos de media literacy, digital literacy, informational literacy (Buckingham, 2005, Rivoltella, 2008).

No contexto da cultura digital, as tecnologias móveis e os meios de comunicação visual, eletrônica e digital estão

redefinindo conhecimentos, habilidades e competências necessárias para a plena participação na sociedade contemporânea, e todas essas habilidades são vistas como fundamentalmente vinculadas às práticas intelectuais e sociais conhecidas como alfabetização. (NEW LONDON GROUP apud HOBBS, 2006, p.20).

Esta noção de alfabetização no sentido das multiliteracies relaciona-se com a perspectiva dos novos letramentos uma vez que envolve novas competências que, por sua vez, solicitam mudanças não apenas no ambiente de aprendizagens, mas na própria concepção destas pautadas no diálogo, na negociação, na participação e na colaboração. Assim, diante da outra possibilidade de entender o modelo 1:1, mencionado anteriormente, os usos de laptop nas escolas podem assumir um caráter em que a autoria colaborativa tenha espaço nos processos de ensino-aprendizagem, de forma dialógica e interacional.

Ao lado da possibilidade de compartilhamento há, ain$\mathrm{da}$, a ideia da conectividade, que se refere a um dos aspectos mais enfatizados na proposta de inclusão digital do ProUCA, como destacam Quartiero, Bonilla e Fantin (2012). Sabemos que uma mediação significativa pode assegurar outras formas de participação na escola e na comunidade, pois a proposta da tecnologia distribuída e a possibilidade de trabalhar de forma cooperativa é um potencial para uma didática inovadora, ressalta Fantin (2012).

Por outro lado, é importante observar que em grande parte das experiências com o ProUCA mencionadas por outras pesquisas (Sampaio e Elia, 2012), tal aspecto ainda está condicionado aos limites técnicos do laptop e da infraestrutura escolar, que na maioria das vezes não permite um uso estruturado e simultaneamente conectado, colocando em cheque seus princípios, como vimos.

A partir de diferentes mediações propostas no contexto da pesquisa micro, é possível tensionar alguns aspectos que Fantin (2012) observou e que dizem respeito às dimensões da interação/interatividade ${ }^{5}$, da aprendizagem colaborativa e das múltiplas linguagens. Isso nos leva a perguntar: em que medida a interatividade propicia uma aprendizagem consistente diante de um fazer superficial que o uso do laptop conectado às redes digitais solicita em certas atividades? A aprendizagem colaborativa realmente estimula o trabalho cooperativo e a autonomia ou apenas requer "participação superficial" na divisão de tarefas? As produções nas múltiplas linguagens (escrita, imagética, audiovisual, digital) propiciam o entendimento das especificidades dos textos, suas linguagens e articulações na perspectiva da cultura da convergência (Jenkins, 2009) ou apenas apresentam-se como justaposições possíveis? 
Ainda não temos respostas, mas é possível elencar algumas pistas a partir de algumas atividades realizadas com crianças no contexto da pesquisa micro desenvolvida por Miranda $(2013)^{6}$ com foco nas múltiplas linguagens e nas multissensorialidades.

\section{Entre múltiplas linguagens e multissensorialidades: dos registros fotográficos ao flipbook}

Para acompanhar o cotidiano das crianças na escola e identificar os usos que elas faziam das tecnologias digitais móveis, nos orientamos por um desenho de uma pesquisa qualitativa que garantisse o contato com as crianças e as tecnologias em sala de aula. Desse modo Miranda (2013) acompanhou o trabalho desenvolvido em uma turma do $3^{\circ}$ ano em uma escola participante do ProUCA durante um semestre letivo. Por meio de observação participante semanal, tivemos elementos para conhecer o grupo e elaborar uma proposta de intervenção didático-pedagógica, como previa a metodologia da pesquisa macro (QUARTIERO, BONILLA, FANTIN, 2012), já mencionada.

Com a intenção de construir as propostas de intervenção em conjunto com a professora da classe, de forma a observar as possibilidades de mediação e uma reflexão sobre o contexto já vivenciado pelas crianças, foram realizadas atividades que abarcaram as múltiplas linguagens e as multissensorialidades, com a mobilização/construção de conhecimentos em diversos suportes e formatos (fotografia, audiovisual, áudio, escrita, imagética, etc.).

Neste trabalho as multissensorialidades são entendidas como possibilidades de interação entre crianças-aprendizagens-conteúdos (visuais, audiovisuais, táteis e motores) mediadas ou não pelas tecnologias, de modo a envolver diversos sentidos e estimular novas percepções e formas de comunicação, em um contexto de colaboração e de educação numa perspectiva ecológica e sistêmica.

No conjunto da realização das atividades que possibilitaram ultrapassar "os muros da escola", as múltiplas linguagens e as multissensorialidades são consideradas como indicadores na busca pela compreensão das interfaces sensoriais e perspectivas nos usos das tecnologias (MIRANDA; FANTIN, 2013). São, também, possibilidades para perceber como os alunos transitam e articulam significados verbais e não-verbais, visuais, espaciais, táteis e outros no contexto social do qual são parte, e que inclui, como não poderia deixar de ser, a escola.

Com a propósito de entender como os usos das tecnologias podem ser mediados em uma perspectiva ecológica e sistêmica da mídia-educação em uma escola participante do ProUCA, buscamos enfatizar as relações de aprendizagem, colaboração e participação por meio de atividades em que se evidenciam competências distribuídas, típicas de uma "nova substância espiritual" (LANKSHEAR E KNOBEL, 2011, p. 40) das "novas formas de pensar" que se alinham às concepções epistemológicas apontadas por Bateson em sua Ecologia da Mente (1986).

Assim, a intervenção didática construída na pesquisa visou o trabalho com as tecnologias em um contexto mais amplo, que envolveu escola, comunidade escolar e bairro. Entre diversas atividades, foram realizadas saídas de campo percorrendo o caminho escola-bairro-escola. Tal processo foi registrado em fotografias, descrito em textos e representado em desenhos, modelos e maquetes ${ }^{7}$. As crianças fizeram entrevistas em grupos - para as quais os alunos escolheram previamente sua "função" entre elas a de repórter, cinegrafista, fotógrafo e assistentes com moradores antigos do bairro que contaram como era o local antigamente e como eles o percebem hoje.

Seguindo a mesma perspectiva participativa, durante uma das atividades da intervenção didática desenvolvida na pesquisa, os alunos sugeriram a confecção de um flipbook, no qual cada um pode contar uma "história em movimento", criando uma narrativa que envolvesse o tema central. Considerado como um brinquedo ótico, o flipbook foi utilizado como ponto de partida para a criação de uma animação em stopmotion, cujas etapas de pré-produção - com a realização de um roteiro coletivo - e produção ${ }^{8}$ - com a captura das imagens e manipulação dos personagens e cenários feitos pelos alunos - foram realizadas em conjunto, buscando hori- 
zontalizar as decisões de alunos, professor e pesquisador (MIRANDA, 2013).

A realização das atividades seguiu um esquema de efetivações e retomadas: em um dia eram feitas as atividades e no outro encontro eram retomadas as questões por meio das imagens em foto ou vídeo. Assim, os registros também foram usados como "disparadores" para a realização de textos, gravações de áudio (entrevistas) e apresentação do flipbook cujas histórias eram narradas oralmente, bem como na construção dos cenários e roteiro coletivo para o stopmotion.

Além de pensar a "substância técnica", também buscamos perceber a "nova substância espiritual", ou seja, entender como as interações possibilitadas e mediadas pelas atividades no contexto escolar incentivaram uma aprendizagem socialmente construída a partir das múltiplas linguagens. Tal aprendizagem se pretendia eficaz, integrada, produtiva e crítica, critérios mencionados por Lankshear e Knobel (2011) e que caracterizam a incorporação das tecnologias digitais móveis aliadas às práticas sociais e culturais em uma escola que se abre ao entorno como um ecossistema comunicativo.

Com as atividades, foi incentivado que os alunos refletissem sobre as práticas e suas relações, seguindo os preceitos da mídia-educação e visando apropriação e da "transferência" de aprendizagem. Isso pode ser percebido quando revíamos as atividades que envolviam o entorno escolar, como as visitas para as entrevistas e o roteiro pelo caminho bairro-escola-bairro. Nesse caso, percebeu-se que o uso de um disparador - as imagens registradas no percurso ou o áudio captado nas entrevistas - contribuiu e fortaleceu a sincronia de aprendizagens que incluem aspectos culturais, tecnológicos e epistemológicos, como afirmam Lankshear e Knobel (2011).

Contudo, em diversos casos, vários alunos nunca, ou pouco, haviam manipulado tecnologias digitais como câmeras digitais, gravadores de áudio no laptop e mesmo o computador da sala informatizada da escola. Nesse cenário, foi possível observar que a pouca familiaridade dificultou e/ou impossibilitou a "livre expressão" em algumas situações, por consequência, a participação efetiva nos Discursos (GEE, 2000). Assim, percebemos que as possibilidades de utilizar as múltiplas linguagens de forma a atuar, participar, valorar e criticar - o que caracteriza uma aprendizagem colaborativa e eficaz com as tecnologias - por vezes transfigurou-se em uma participação superficial e não integrada. Ou seja, o sentido de aprendizagem colaborativa entendida como negociação social e diálogo que favoreça processos de aprendizagens em que os alunos estejam bem informados, planejem e tomem decisões compartilhadas, como destaca Fantin (2013b), deixou a desejar.

Contudo, foi o flipbook, o "livrinho analógico" (MIRANDA, 2013 , p. 128) que mais suscitou a curiosidade e a participação dos alunos. Nesta atividade de criação visual artesanal, proposta como uma possibilidade de entendimento do mecanismo e da lógica do stopmotion e realizada a pedido dos alunos, foi possível perceber uma aprendizagem eficaz oportunizada pela reflexão das diferentes formas expressivas (MIRANDA; FANTIN, 2013). As hipóteses e os motivos de tal "encantamento" podem ser diversos: a curiosidade com o artesanal; a possibilidade de a manipulação do analógico ser mais interessante do que a do digital, como por exemplo, a câmera; a provável autoria nas múltiplas linguagens; ou ainda, a descoberta do complexo princípio da imagem em movimento. Talvez tudo isso e muito mais.

Ao pensar a multissensorialidade permeando o uso do laptop e a ênfase nas múltiplas linguagens em uma escola participante do ProUCA, na qual os alunos não estavam familiarizadas com as tecnologias digitais, novas questões aparecem. O que parecia improvável nesse contexto multitela da cultura digital toma novos contornos sobre a obsolescência da escola e nos leva a perguntar se mesmo quando se traveste com as possibilidades das tecnologias digitais móveis a escola continua sendo uma "máquina antiquada", como destaca Sibilia (2012, p. 197), e/ou pergunta Jost (2011):"novos comportamentos para antigas mídias ou antigos comportamentos para novas mídias? 
Talvez a resposta possa estar na fala de um menino que participou da pesquisa mais ampla, e quando perguntado sobre o que mudou na escola com o ProUCA, respondeu: "a escola continua a mesma, só está mais tecnológica" (in FANTIN, 2013a).

\section{Algumas considerações e novos desdobramentos}

Ao tensionar o uso das tecnologias digitais móveis no âmbito escolar, foi possível perceber que, para pensar a inserção dos artefatos na escola, é preciso ponderar a relação desta com a comunicação e superar a concepção das mídias como simples ferramentas e instrumentos. Para tanto, escola, professores, alunos e pesquisadores necessitam, antes, mergulhar nos meandros da comunicação contemporânea, como apontou Martin-Barbeiro (2004).

No entanto, essa ideia não é nova e nos remete à Freinet e a sua pedagogia (1974) que, ao questionar as linguagens de sua época e a importância de tal apropriação na escola ainda na década de 1940, propôs uma práxis concreta, modificando as relações entre alunos e professores no espaço da escola e fora dela, de forma a agenciar uma "intercomunicação" pautada nas trocas dialógicas. Diálogo também enfatizado por Freire, na década de 1960. Autores que são referências da mídia-educação e que continuam a inspirar uma diversidade de práticas educativas.

Vimos que sem pensar a dinâmica que caracteriza um paradigma ecológico e sistêmico, a simples adoção das tecnologias no fazer pedagógico incidirá no risco de se travestir em uma obrigação descontextualizada e mecânica frente ao modo de fazer, refazer e co-fazer dinâmico que o contato com as tecnologias digitais adquirem "fora" da escola (MIRANDA, 2012). Assim, a possibilidade de pensar Educação e Comunicação para além da relação linear e instrumental passa pela percepção de seu entrelaçamento, no sentido de uma mídia-educação.

Na perspectiva ecológica e sistêmica da mídia-educação, as mediações entre crianças, tecnologias digitais móveis, escola e cultura se constroem de diversas maneiras na perspectiva de uma apropriação contextualizada, crítica e criadora. As aprendizagens que ali ocorrem são múltiplas, assim como as linguagens e sensorialidades, e se expressam desde um mero "livrinho analógico" ao mais moderno tablet. Aprendizagens que se constroem e reconstroem em interação com o outro, com o ambiente e com os dispositivos e artefatos que ainda virão.

Além disso, a problematização dos limites entre as aprendizagens que ocorrem "dentro" e "fora" da escola nos parece uma questão seminal. Ampliar os saberes, os fazeres, bem como a participação na busca por uma aprendizagem ao longo da vida são tendências da mídia-educação contemporânea (RIVOLTELLA, 2012a). Assim, é no âmbito do ensino-aprendizagem que a mídia-educação com abordagem culturalista propõe a superação dos usos das tecnologias sob um viés determinista e pautado apenas na instrumentalização.

Os desdobramentos desta e de outras questões que emergiram em pesquisas anteriores - entre elas a pesquisa UCABASC, bem como da dissertação de mestrado da qual este artigo é fruto -, fazem parte de um novo conjunto de investigações. Assim, seguindo o mesmo caráter coletivo, participativo e de intervenção didáti$\mathrm{ca}$, a pesquisa Multiletramentos e aprendizagens formais e informais: possíveis diálogos entre contextos escolares e culturais (FANTIN, 2014) busca analisar as percepções e práticas de crianças e jovens no âmbito da cultura digital e no contexto das multiliteracies e da aplicação de uma nova metodologia, os Episódios de Aprendizagem Situada, EAS (RIVOLTELLA, 2013). Aliada a esta, o interesse pela construção de competências midiáticas e digitais de estudantes e professores articula-se com a investigação Competências midiáticas em cenários brasileiros e euroamericanos (BORGES, 2014), desenvolvida em parceria com diversas instituições nacionais (UJFJ, UNB, UFF, UFTM, UEPG, UFSC) e internacionais por meio da Rede Alfamed.

Desse modo, no intuito de inferir possíveis diálogos entre os conhecimentos que transitam em contextos formais $e$ informais de aprendizagem, as pesquisas entrelaçadas à investigação macro buscarão, ainda, refletir sobre a metodologia dos Episódios de Aprendizagem Situada, EAS, 
(RIVOLTELLA, 2013) e sua aplicação na especificidade de diferentes contextos escolares com estudantes de diversas faixas etárias, disciplinas e níveis de ensino. De forma breve, a metodologia EAS se caracteriza por propor, a partir de um ponto de vista didático e neurodidático (RIVOLTELLA, 2012B) uma intervenção que situa o aluno, os professores (e no nosso caso, também os pesquisadores) em toda a sua corporeidade, constituídos e ao mesmo tempo constituidores de um contexto educativo imerso na complexidade. Esta perspectiva "sugere um trabalho com conteúdos circunscritos e organizados em torno de atividades breves de produção, emolduradas por instruções prévias e reflexões posteriores que modificam o desenho da aula, do planejamento e da avaliação" (FANTIN, 2015, p.1).

Ainda como premissa, entendemos que estas novas possibilidades de ensino-aprendizagem buscam a "singularidade na multiplicidade": múltiplas linguagens, multissensorialidades, multiletramentos e múltiplas competências para ser, estar, ensinar e aprender em um contexto igualmente múltiplo, que acentua a dimensão da corporeidade ao expandir as possibilidades de produção de sentidos e de significados. Nesse caminho de desdobramentos e descobertas, a tarefa que primeiro nos aparece diz respeito à necessidade de ampliar o conceito de ensino-aprendizagem para, só então, percebê-lo de uma forma plural. Do mesmo modo, a necessidade de ressignificar o entendimento e o conceito de competência no sentido de múltiplas competências que se constroem nesse percurso. Assim, para reafirmar e (re)incluir a corporeidade nas novas possibilidades didáticas e pedagógicas da abordagem ecológica e sistêmica da mídia-educação é importante considerar as práticas, as habilidades e as atitudes que emergem da interação, produção e compartilhamento de conhecimentos desta que é uma nova cultura. Uma cultura digital.

\section{Notas}

1 Ao ser tomada pelo viés das Ciências Sociais, a Comunicação é entendida como um "movimento orquestral", tal como postulado pelos membros do Colégio Invisível (WINKIN 1981). Colégio Invisível é forma como é nomeado um grupo de pesquisadores que se ligam por interesses conceituais e metodológicos, não institucionais. Assim foi chamado o grupo de pesquisadores encabeçados por Gregory Bateson que, a partir da década de 50, se uniram por meio de uma teia que pondera a comunicação como um processo social. Trazendo suas questões para o campo das ciências sociais, o grupo, mesmo ativo na realização de pesquisas sobre o assunto que os unia, poucas vezes se reuniu.

2 Disponível em <http://www.planalto.gov.br/ccivil_03/_ ato2007-2010/2010/lei/l12249.htm> Acesso em 01. Abr. 2012

3 Mesmo sem ter os dados das pesquisas que estão avaliando tal projeto, o próprio Ministério da Educação já distribui cerca de 380 mil tablets nas escolas em 2013, e estima-se a continuidade da distribuição entre professores e alunos do nível médio (tablets com telas de 7 e 9,7 polegadas, 16Gb de memória e processador de $1 \mathrm{Ghz}$ ) em escolas de todos os estados da Federação e do Distrito Federal. Dados divulgados em matéria disponível na página do FNDE http://goo.gl/xihn08

4 A pesquisa UCABASC - coordenada por Elisa Quartiero (UDESC), Maria H. Bonilla (UFBA) e Monica Fantin (UFSC) - foi uma investigação interinstitucional que reuniu pesquisadores da Universidade Federal de Santa Catarina (UFSC), Universidade Federal da Bahia (UFBA) e Universidade do Estado de Santa Catarina (UDESC). A pesquisa incluiu no seu escopo macro pesquisas individuais de mestrado e doutorado, constituindo-se em um espaço tanto de investigação como de formação.

5 Para Bateson (1977), os seres vivos estão em constante interação, o que possibilita as trocas e a comunicação de forma ecológica. Assim, não são resistentes às mudanças ou diferenças (que ele entende como informação), mas incide sobre elas, seja incorporando-as ou corrigindo-as. Nesse contexto, consideramos aqui a dimensão da interatividade, ou seja, a interação mediada pela tecnologia e acesso à internet.

6 As pesquisas individuais que se relacionaram à pesquisa UCABASC podem ser consideradas contextos micros, partes de um contexto maior de pesquisa, uma vez que este promoveu um intenso compartilhamento de ideia, conceitos, propostas e experiências.

7 A dissertação de mestrado Multissensorialidades e aprendizagens: usos das tecnologias móveis pelas crianças na escola (2013), foi apresentada no Programa de Pós-graduação em Educação, da Universidade Federal de Santa Catarina (PPGE/UFSC) e realizada sob orientação da professora Dra. Monica Fantin.

8 A etapa de pós-produção do audiovisual foi realizada pela pesquisadora. 


\section{Referências}

BATESON, Gregory. Una unidad sagrada. Pasos ulteriores hacia una ecologia de la mente. Barcelona: Editorial Gedisa, 1993.

BATESON, Gregory. Mente e natureza. Rio de Janeiro: Francisco Alves Editora, 1986.

BATESON, Gregory.. Steps to an ecology of mind. Library of Congress Cataloging-in-Publication Data, 1977.

BONILLA, Maria. Helena.; PRETTO, Nelson. Inclusão digital. Polêmica contemporânea. Salvador: EDUFBA, 2011, v.2.

BORGES, Gabriela. Competências midiáticas em cenários brasileiros e euroamericanos. Projeto de Pesquisa. CNPq, 2014.

BRASIL/MEC/FNDE. RESOLUÇÃO/FNDE/CD/N 17 DE 10 DE JUNHO DE 2010. Estabelece normas e diretrizes para que os Municípios, Estados e o Distrito Federal se habilitem ao Programa Um Computador por Aluno - PROUCA.

BRASIL/MEC/SEED. UCA: Uma visão sintética dos processos de avaliação e formação. Brasília, 2010.

BRUNER, Jerome. A cultura da educação. Porto Alegre: Artmed, 2001.

BUCKINGHAM, David. Crescer na era das mídias eletrônicas. São Paulo: Edições Loyola, 2007.

BUCKINGHAM, David. Media Education: literacy, learning and contemporary culture. Cambridge: Polity Press, 2005.

FANTIN, Monica. Novos Paradigmas da Didática e a Proposta Metodológica dos Episódios de Aprendizagem Situada, EAS. Educação \& Realidade, Porto Alegre, v. 40, n. 2, p. 443-464, abr./jun. 2015. Disponível em http://seer.ufrgs.br/index.php/ educacaoerealidade/article/view/46056/33409.

FANTIN, Monica. Multiletramentos e aprendizagens formais e informais: possiveis diálogos entre contextos escolares e culturais. Projeto de Pesquisa. CNPq, 2014.

FANTIN, Monica. Alunos-Laptop na Escola: práticas e diálogos possíveis. In II Seminário UCABASC. UFBA, Salvador, $2013 a$.

FANTIN, Monica . O trabalho em rede e a aprendizagem colaborativa. In Anais da 10 a. Jornatec: Jornada Catarinense de Tecnologia Educacional. Florianópolis, SESC, 2013b. (p.97-104).

FANTIN, Monica. Cultura digital e aprendizagem multimídia com o uso de laptop na escola. In Revista Educação On-line. Rio de Janeiro, n 11, 2012 (pp. 89-105).

FANTIN, Monica. Mídia-educação: conceitos, experiências, diálogos Brasil-Itália. Florianópolis: Cidade Futura, 2006.

FANTIN, Monica; GIRARDELLO, Gilka Elvira Ponzi. Diante do abismo digital: mídia-educação e mediações culturais. Perspectiva, Florianópolis, v. 27, n. 1, p. 69-96, abr. 2009. ISSN 2175-795X. Disponível em: <https://periodicos.ufsc.br/index.php/perspectiva/article/view/2175-795X.2009v27n1 p69>. Acesso em: 20 Jun. 2015.

FREIRE, Paulo. Extensão ou comunicação? São Paulo: Paz e Terra, 2011.

FREINET, Celéstin. O Jornal escolar. Lisboa: Editorial Estampa, 1974.

GEE, James Paul. Discourse and sociocultural studies in reading. In M.L. Kamil, P.B. Mosenthal, P.D. Pearson, \& R. Barr (Orgs.) Handbook on reading research, v. III (pp. 195-208). London: Routledge, 2000.

GEE, James Paul. The social mind: Language, ideology, and social practice. New York: Bergin \& Garvey, 1992.

JENKINS, Henry. Cultura da Convergência. 2a. ed. São Paulo: Aleph, 2009.

JOST, François. Novos comportamentos para antigas mídias ou antigos comportamentos para novas mídias? In Matrizes, v 4 n. 2, jan./jun. 2011, p. 93-109.

KERCKHOVE, Derrick de. A pele da cultura. São Paulo: Annablume, 2009.

LANKSHEAR, Colin.; KNOBEL, Michele. Nuevos Alfabetismos. Su prática cotidiana y el aprendizaje en el aula. $3^{\circ}$ edición. Madrid: Ediciones Morata, 2011.

MARTÍN-BARBERO, Jesus . Ofício de cartógrafo. Travessias latino-americanas da comunicação na cultura. São Paulo: Edições Loyola, 2004.

MARTÍN-BARBERO, Jesus. Desafios culturais da comunicação à educação. Revista Comunicação e Educação. São Paulo, n. 18, maio./ago, 2000. p. 51- 61 Disponível em http://www.revistas.univerciencia.org/index.php/comeduc/article/viewArticle/4108 Acesso em: 07. Out.2010.

MIRANDA, Lyana Thédiga. Multissensorialidades e aprendizagens: usos das tecnologias móveis pelas crianças na escola. Dissertação (Mestrado), Programa de Pós-Graduação em Educação, Universidade Federal de Santa Catarina, 2013a.

MIRANDA, Lyana Thédiga; FANTIN, M. Crianças e tecnologias móveis na escola: interação e mediação, In Anais do XIII Encontro dos Grupos de Pesquisas em Comunicação, do XXXVI Congresso Brasileiro de Ciências da Comunicação, INTERCOM. Manaus, 2013.

MIRANDA, Lyana Thédiga. A linguagem de nossa época: o relato de uma experiência com o jornal impresso na formação inicia. Revista EntreVer, Florianópolis, v. 2, n. 3, p. 52-65, jul/ dez, 2012. Disponível em: http://incubadora.periodicos.ufsc.br/ index.php/EntreVer/article/view/2002.

NEW LONDON GROUP. A Pedagogy of Multiliteracies: Designing Social Futures. Harvard Educactional Review. v. 66, n. 1, Massa- 
chusetts, 1996. Disponível em: http://www.newliteracies.com. au/what-are-new-literacies?/138/ Acesso em: 15. Out. 2011.

PAPERT, Seymour. A máquina das crianças. Porto Alegre: Artmed, 2008.

PINTO, Manuel. A busca da comunicação na sociedade multi-ecrãs: perspectiva ecológica. In Comunicar, 25, 2005 (p.259-264).

QUARTIERO, Elisa.; BONILLA, Maria Helena, FANTIN, Monica. Políticas para la inclusión de lãs TIC em lãs escuelas públicas brasileñas: contexto y programas. In, Campus virtuales, v. 1, n 1, 115 - 126, 2012. Disponível em: http://issuu.com/revistacampusvirtuales/docs/revista_campusvirtuales_01/115?mode=window\&printButtonEnabled=false\&backgroundColor $=\% 23222222$ Acesso em: 08. Fev. 2013.

RIVOLTELLA, Pier Cesare. Fare Didattica con gli EAS. Episodi di Aprendimento Situati. Brescia: Editrice La Scuola, 2013.

RIVOLTELLA, Pier Cesare. Retrospectivas e tendências da pesquisa em mídia-educação no contexto internacional. In FANTIN, M.; RIVOLTELLA, P.C.. Cultura digital e escola: pesquisa e formação de professores. Campinas: Papirus, 2012(a).

RIVOLTELLA, Pier Cesare . Neurodidattica. Insegnare al cervello che apprende. Milão: Rafaello Cortina Editore, 2012(b).

RIVOLTELLA, Pier Cesare . Midia-educação e pesquisa educativa. Perspectiva, Florianópolis, v. 27, n. 1, p. 119-140, abr. 2009. ISSN 2175-795X. Disponível em: <https://periodicos. ufsc.br/index.php/perspectiva/article/view/2175-795X.2009v27n1p119>. Acesso em: 05 Jul. 2015. doi:http://dx.doi.org/10.5007/2175-795X.2009v27n1p119.

RIVOLTELLA, Pier Cesare (ed). Digital Literacy. Tools and Methodologies for Information Society. New York: IGI Publishing, 2008.

SAMPAIO, Fábio Ferrentini.; ELIA, Marcos Fonseca. Projeto Um Computador Por aluno. Pesquisas e Perspectivas. Rio de Janeiro: NCE/UFRJ, 2012. Disponível em http://www.nce.ufrj.br/ ginape/livro-prouca/LivroPROUCA.pdf

SEVERIN ,Eugenio; CAPOTA, Christine. La computación uno a uno: nuevas perspectivas. In Revista Iberoamericana de Educación, n. 56, 2011 (pp. 31-48).

SIBILIA, Paula. A escola no mundo hiperconectado: redes em vez de muros? Revista Matrizes. Ano 5 - n 2 - jan./jun São Paulo. 2012 - (p. 195-211).

THIOLLENT, Michel. Metodologia da pesquisa-ação. São Paulo: Cortez, 2000.

TRIPP, David. Pesquisa-ação: uma introdução metodológica. Educação e Pesquisa, São Paulo, v. 31, n. 3, set./dez. 2005, p. 443-466. Disponível em: http://www.scielo.br/pdf/ep/v31n3/ a09v31n3.pdf Acesso em: 28. Nov. 2012.
WARSCHAUER, Mark. Tecnologia e inclusão social: a exclusão digital em debate. São Paulo: Editora Senac, 2006.

WINKIN, Yves. La nouvelle communication. Paris: Éditions Du Seuil, 1981.

Recebido em 07 de julho de 2015.

Aceito em 01 de setembro de 2015. 
